Agrika: Jurnal Ilmu-Ilmu Pertanian, Volume 14, Nomor 1, Mei 2020

\title{
ANALISIS PENDAPATAN USAHATANI PADI CIHERANG DAN IR.64 DI KECAMATAN BANYUBIRU, KABUPATEN SEMARANG
}

\section{ANALYSIS OF CIHERANG AND IR.64 RICE FARMING REVENUE IN BANYUBIRU DISTRICT, SEMARANG DISTRICT}

\author{
Stanie Aster Wijaya ${ }^{1)}$, Lasmono Tri Sunaryanto ${ }^{2)}$ dan \\ Hendrik Johanes Nadapdap ${ }^{3)}$ \\ Fakultas Pertanian dan Bisnis, Universitas Kristen Satya Wacana \\ E-mail: stanieaster@yahoo.com
}

\begin{abstract}
ABSTRAK
Dalam pengembangan dunia pertanian, Indonesia terus mengembangkan beragam varietas padi. Hal ini karena pertumbuhan penduduk yang cukup pesat, produksi beras Indonesia tidak mampu mencukupi kebutuhan dalam negeri sehingga perlu dilakukan impor beras. Penelitian ini bertujuan mengetahui faktor yang berpengaruh pada pendapatan usahatani padi dan membandingkan pendapatan usahatani padi antara varietas Ciherang dengan IR.64. Dilihat dari geografisnya, Kabupaten Semarang cukup strategis dan memiliki potensi wilayah dalam peningkatan produksi beras. Di Kecamatan Banyubiru, Kabupaten Semarang, petani lebih memilih varietas Ciherang dan IR64 untuk ditanam karena sesuai dengan faktor lingkungan pertumbuhan dan perkembangan tanaman, seperti suhu, struktur tanah, jenis tanah, $\mathrm{pH}$ tanah dan iklim. Hasil penelitian menunjukkan varietas Ciherang pada indikator benih lebih efektif dibandingkan varietas IR.64 dengan p-value < 0,05. Sedangkan untuk varietas IR.64 indikator pupuk, tenaga kerja, dan pestisida lebih efektif dibandingkan dengan varietas Ciherang dengan $\mathrm{p}$-value $<0,05$.
\end{abstract}

Kata Kunci: Analisis Pendapatan; Padi Ciherang; Padi IR.64; Usahatani

\begin{abstract}
In developing of agriculture, Indonesia continues to develop a variety of rice varieties. This is because the population growth is quite rapid, so that Indonesia rice production is not able to meet domestic needs so it requires importing rice from other countries. This study aims to determine the factors that influence rice farming income and compare it between Ciherang and IR.64 varieties. From its geography, Semarang Regency is quite strategic and has the potential of the region in increasing rice production. In Banyubiru District, Semarang Regency, farmers prefer Ciherang and IR.64 varieties to be planted because they are in accordance with environmental factors with plant growth and development, such as temperature, soil structure, soil type, soil pH and climate. The results showed that the Ciherang variety in the seed indicator was more effective than the IR.64 variety with p-value <0.005. Whereas for IR.64 varieties, fertilizer, labor and pesticide indicators were more effective than Ciherang varieties with $p$-value $<0.05$.
\end{abstract}

Keywords: Farming; Revenue Analysis; Rice Ciherang; Rice IR.64 


\section{PENDAHULUAN}

Dalam dunia pertanian, Indonesia terus mengembangkan beragam varietas padi. Hal ini karena pertumbuhan penduduk yang cukup pesat. Produksi beras Indonesia tidak mampu mencukupi kebutuhan dalam negeri sehingga mengharuskan melakukan impor beras. Beras sebagai bahan makanan pokok, produksinya perlu terus ditingkatkan untuk memenuhi kebutuhan pangan. Petani padi di Kecamatan Banyubiru, Kabupaten Semarang lebih memilih menanam padi varietas IR.64 karena usia panen yang lebih cepat serta ketahanan terhadap serangan hama dan penyakit jika dibandingkan dengan padi varietas Ciherang. Berdasarkan pengalaman petani di Desa Kebondowo, padi varietas Ciherang dikenal memiliki kualitas beras yang lebih baik dan produktifitas yang tinggi jika dibandingkan dengan padi varietas IR.64.

Ketahanan, kemandirian, dan kedaulatan pangan Indonesia dinilai belum kokoh. Hal ini diindikasikan oleh tingginya impor produk pangan. Sepanjang Januari-Oktober 2017 impor beras Indonesia mencapai 256,56 ribu ton dengan nilai US\$ 119,78 juta. Jumlah tersebut jauh lebih rendah dibanding impor periode Januari-Desember 2016 seberat 1,28 juta ton dengan nilai US\$ 531,84 juta. Dalam periode tahun 2016 jumlah impor pangan masih tinggi meskipun mengalami penurunan di tahun 2017. Hal tersebut mengindikasikan bahwa Indonesia mulai semakin membaik dalam mencukupi kebutuhan produksi beras dalam negeri (BPS, 2017).

$$
\text { Petani dalam melakukan }
$$
usahataninya mengharapkan agar setiap rupiah yang dikeluarkan akan menghasilkan pendapatan yang sebanding. Namun demikian, tinggi rendahnya pendapatan yang dihasilkan atau yang diterima petani tergantung pada biaya produksi selama kegiatan usahatani berlangsung dan jumlah produksi yang dihasilkan.

Keunggulan suatu varietas dibatasi oleh berbagai faktor, termasuk penurunan ketahanannya terhadap hama dan penyakit tertentu setelah dikembangkan dalam periode tertentu. Varietas IR-64 yang semula tahan hama wereng coklat, misalnya, akhir-akhir ini telah menurun ketahanannya. Jika varietas ini ditanam terus-menerus dikhawatirkan akan terserang oleh hama tersebut. Oleh sebab itu, Pusat Penelitian dan Pengembangan (Puslitbang) Tanaman Pangan melalui Balai Penelitian Tanaman Padi (Balitpa) berupaya merakit varietas unggul baru 
dengan sifat-sifat yang lebih baik (BBPADI, 2015).

Kabupaten Semarang memiliki lahan yang luas sehingga menjadi penopang ketersediaan pangan Provinsi Jawa Tengah. Dilihat dari geografisnya, Kabupaten Semarang cukup strategis dan memiliki potensi wilayah dalam peningkatan produksi beras. Di Kecamatan Banyubiru, Kabupaten Semarang, petani lebih memilih varietas Ciherang dan IR.64 untuk ditanam karena sesuai dengan faktor lingkungan bagi pertumbuhan dan perkembangan tanaman seperti suhu, struktur tanah, jenis tanah, $\mathrm{pH}$ tanah dan iklim.

Benih padi varietas Ciherang umur tanamannya bisa mencapai 116-125 hari dan tinggi tanaman padi antara 105-107 $\mathrm{cm}$. Padi varietas Ciherang cocok ditanam pada dataran rendah dengan ketinggian $500 \mathrm{~m} \mathrm{dpl}$, dan juga tahan terhadap penyakit hawar daun. Sementara varietas IR.64 juga dapat tumbuh dengan baik seperti umur tanaman 115 hari, anakan produktif cukup banyak. Padi varietas IR.64 ini juga tahan terhadap penyakit yang disebabkan bakteri hawar (Suprihatno, 2009).

Penelitian ini bertujuan untuk mengetahui pendapatan yang diperoleh petani dan apakah terdapat perbedaan pendapatan petani varietas Ciherang dan IR.64 terkait faktor yang mempengaruhi perbedaan pendapatan, yaitu benih, pupuk, tenaga kerja dan pestisida.

\section{METODE PENELITIAN}

Penelitian ini dilakukan di Desa Kebondowo, Kecamatan Banyubiru, Kabupaten Semarang. Pemilihan tempat penelitian dilakukan secara sengaja (purposive) dengan pertimbangan bahwa Kecamatan Banyubiru merupakan wilayah yang menghasilkan padi paling banyak di Kabupaten Semarang. Penelitian dilakukan pada bulan JanuariFebruari 2019.

Penelitian dilakukan dengan pendekatan kuantitatif menggunakan kuesioner yang dipandu dengan wawancara dan mendeskrispikan masalah, mengumpulkan data, menganalisis data dan selanjutnya menarik kesimpulan. Responden yang diambil dari penelitian ini yaitu 60 orang dengan jumlah petani yang menanam padi varietas Ciherang sebanyak 30 orang dan varietas IR.64 sebanyak 30 orang dengan menggunakan pendekatan probability sampling. Probability sampling adalah teknik pengambilan sampel yang memberikan peluang yang sama bagi setiap unsur (anggota) populasi 
untuk menjadi anggota sampel

D : Dummy variabel

(Sugiyono, 2010). Teknik probability sampling yang digunakan adalah simple random sampling.

Sumber data pada penelitian ini, yaitu data sekunder. Data sekunder yang diperoleh langsung dari petani di lahan melalui wawancara. Analisis keuntungan usaha tani padi sawah di desa Banyubiru Kecamatan Banyubiru Kabupaten Semarang yang digunakan dalam penelitian ini adalah sebagai berikut:

\section{Analisis regresi linier berganda}

Metode analisis regresi linier berganda dengan variabel dummy untuk mengetahui faktor yang mempengaruhi perbedaan pendapatan antara usahatani varietas Ciherang dan IR.64 dengan persamaan sebagai berikut :

$\ln \pi=\ln \alpha+\alpha_{1} \ln \mathrm{X}_{1}+\alpha_{2} \ln \mathrm{P}_{2}+\alpha_{3} \ln$ $\mathrm{P}_{3}+\alpha_{4} \ln \mathrm{P}_{4}+\alpha_{5} \ln \mathrm{X}+\mathrm{D}+e$

Di mana:

$\pi$ : pendapatan(Rp/luas lahan usahatani)

$\alpha$ : intersep

$e:$ kesalahan (error)

$\alpha_{\mathrm{i}}$ : parameter input variabel

$\mathrm{X}_{1}$ : harga benih (Rp/harga output)

$\mathrm{X}_{2}$ : harga pupuk (Rp/harga output)

$\mathrm{X}_{3}$ : harga tenaga kerja (Rp/harga output)

$\mathrm{X}_{4}$ : pestisida (Rp/harga output) 


\section{R/C Rasio}

Analisis pendapatan usahatani padi varietas Ciherang dan IR.64 dengan menggunakan R/C Rasio.

\section{HASIL DAN PEMBAHASAN}

\section{Uji Normalitas}

Hasil uji normalitas menggunakan uji Kolmogorov-Smirnov $Z$ pada varietas Ciherang sebesar 0,956 sedangkan pada varietas IR.64 sebesar 0,985. Hasil menunjukkan nilai yang lebih besar dari alpha 0,05 yang artinya residual berdistribusi normal.

\section{Uji Multikolinearitas}

Uji Multikolinearitas bertujuan menguji model regresi ditemukan adanya korelasi antar variabel bebas (Ghozali, 2001). Dalam penelitian ini digunakan untuk mendeteksi ada atau tidaknya multikolinearitas di dalam model regresi. Jika nilai nilai tolerance mendekati 1 , serta nilai VIF di sekitar angka 1 serta tidak lebih dari 10, maka dapat disimpulkan tidak terjadi multikolinearitas antara variabel bebas (Singgih, 2000). Pada varietas Ciherang dan IR.64 dari variabel X1, X2, X3 dan X4 menunjukkan nilai VIF di bawah 10 yang artinya nilai tolerance tidak terbukti multikolinearitas.

\section{Uji Heteroskedastisitas}

Hasil uji heteroskedastisitas pada setiap variabel dari varietas Ciherang maupun IR.64 menunjukkan nilai signifikansi lebih dari 0,05 yang artinya tidak terbukti heteroskedastisitas.

\section{Faktor yang Mempengaruhi Pendapatan Usahatani Padi Varietas Ciherang dan IR.64}

Faktor-faktor yang mempengaruhi pendapatan usahatani padi varietas Ciherang dan IR.64 yaitu harga benih (X1), harga pupuk (X2), harga tenaga kerja (X3), dan harga pestisida (X4). Variabel tersebut telah diuji menggunakan uji regresi linier berganda, disajikan dalam Tabel 1. Berdasarkan hasil uji korelasi diketahui indikator harga benih diperoleh p-value sebesar $0,131>\alpha(0,05)$ menunjukkan harga benih tidak berpengaruh terhadap pendapatan. Untuk indikator harga pupuk diperoleh p-value sebesar $0,000<\alpha$ $(0,05)$ menunjukkan harga pupuk mempengaruhi pendapatan. Pada indikator harga tenaga kerja diperoleh pvalue sebesar $0,001<\alpha(0,05)$ menunjukkan harga tenaga kerja mempengaruhi pendapatan. Pada indikator harga pestisida diperoleh p- 
value sebesar $0,439>\alpha(0,05)$ p-value sebesar $0,001<\alpha(0,05)$ yang menunjukkan harga tenaga kerja tidak menunjukkan dummy variabel berpengaruh terhadap pendapatan. mempengaruhi pendapatan.

Sedangkan dummy variabel menunjukkan

Tabel 1. Faktor yang Mempengaruhi Pendapatan Usahatani Padi Varietas Ciherang dan IR.64

\begin{tabular}{cllll}
\hline Variable & Coefficient & Std. Error & t-Statistic & Probability \\
\hline Y & 1,412 & 0,000 & 1,799 & 0,078 \\
LnX1 & 7,212 & 0,000 & 1,533 & 0,131 \\
LnX2 & $-0,01$ & 0,000 & $-5,778$ & $0,000^{* *}$ \\
LnX3 & $-7,355$ & 0,000 & $-3,680$ & $0,001^{* *}$ \\
LnX4 & 1,473 & 0,000 & 0,779 & 0,439 \\
D & 2,676 & 0,756 & 3,541 & $0,001^{* *}$ \\
\hline R-squared & 0,793 & & & \\
Adj. R-squared & 0,773 & & & \\
F-tabel & 2,69 & & &
\end{tabular}

Keterangan :

LnX1 : Harga benih

LnX2 : Harga pupuk

LnX3 : Harga tenaga kerja

LnX4 : Harga pestisida

D : Dummy variabel

** : Signifikan pada $\alpha: 0,05(5 \%)$ 
Persamaan hasil analisis regresi faktor-faktor yang mempengaruhi pendapatan usahatani padi varietas ciherang, yaitu :

$$
\begin{gathered}
\mathrm{Y}=1,412+7,212 \ln \mathrm{X} 1-0,01 \ln \mathrm{X} 2- \\
7,355 \ln \mathrm{X} 3+1,473 \ln \mathrm{X} 4+2,676 \mathrm{D} .
\end{gathered}
$$

Nilai R-squared yang diperoleh sebesar 0,793 menunjukkan $79 \%$ dapat dijelaskan pada variabel harga benih (X1), harga pupuk (X2), harga tenaga kerja (X3), dan harga pestisida (X4) sedangkan $21 \%$ dijelaskan oleh faktor lain diluar model variabel. Harga benih tidak berpengaruh terhadap pendapatan karena benih mendapat subsidi dari Pemerintah dengan kualitas yang kurang baik sehingga hasil panen menjadi sedikit dan pendapatan menjadi berkurang. Hal ini sejalan dengan penelitian Listiani, et al., (2019) yang menyatakan bahwa harga benih atau bibit padi tidak berpengaruh terhadap pendapatan petani. Dengan arah korelasi positif di mana semakin tinggi harga benih maka pendapatan petani semakin banyak. Hasil penelitian ini sejalan dengan penelitian Cahyono (2010) yang mengatakan bahwa bibit padi merupakan gabah yang dihasilkan dengan cara dan tujuan khusus untuk disemaikan menjadi pertanaman. Kualitas benih itu sendiri akan ditentukan dalam proses perkembangan dan kemasan benih.

Harga pupuk berpengaruh terhadap pendapatan karena tidak mendapatkan subsidi dari Pemerintah. Dengan arah korelasi negatif dimana semakin tinggi harga pupuk maka pendapatan petani lebih rendah. Pupuk ini yang nantinya akan digunakan petani untuk mencukupi kebutuhan unsur hara pada tanaman. Hasil penelitian ini sejalan dengan Cahyono (2010) unsur hara yang terkandung pada setiap bahan untuk melengkapi unsur hara yang ada pada tanah yang diperlukan tanaman. Tujuan penggunaan pupuk adalah untuk mencukupi kebutuhan makanan (hara) pada tanaman.

Harga tenaga kerja berpengaruh terhadap pendapatan karena tenaga kerja berasal dari dalam keluarga sehingga tidak perlu mengeluarkan tambahan biaya untuk tenaga luar keluarga. Dengan arah korelasi negatif dimana semakin tinggi harga tenaga kerja maka pendapatan petani lebih rendah. Hasil penelitian ini sejalan dengan Shinta (2011) yang mengatakan tenaga kerja manusia dapat dibedakan menjadi tenaga kerja dalam keluarga dan tenaga kerja di luar anggota keluarga. Tenaga kerja di dalam keluarga 
adalah tenaga kerja yang masih anggota keluarga, misalnya ayah, ibu dan anakanak. Tenaga kerja di dalam keluarga umumnya tidak mendapatkan upah. Sedangkan tenaga kerja di luar keluarga adalah tenaga kerja yang mendapatkan upah atas hasil kerjanya. Pembayaran upah tenaga kerja tersebut dapat harian atau borongan, dapat berbentuk uang ataupun hasil panen. Menurut (Suparmoko, 2002) tenaga kerja adalah penduduk dalam usia kerja atau jumlah seluruh penduduk dalam suatu negara dalam memproduksi barang atau jasa, tenaga kerja yang dalam usia kerja yaitu antara 15-64 tahun.

Harga pestisida tidak berpengaruh terhadap pendapatan karena penggunaan pestisida yang sedikit dan kurang efektifnya pembasmian hama sehingga berpengaruh terhadap hasil panen dan pendapatan menjadi berkurang. Triharso (2004) yang mengatakan bahwa Pestisida adalah substansi kimia yang digunakan untuk membunuh atau mengendalikan berbagai hama dalam arti luas (jazad pengganggu).

\section{Pendapatan Usahatani Padi Varietas Ciherang dan IR.64 dengan R/C Rasio}

Berdasarkan hasil Independent Samples Test diperoleh nilai p-value untuk indikator benih $0,000<\alpha 0,05$, menunjukkan bahwa terdapat perbedaan yang signifikan antara kelompok padi varietas Ciherang dan IR.64. Hal ini menunjukkan kelompok padi varietas Ciherang lebih efektif dengan rerata 1,15 $\mathrm{m}^{2}$ dibandingkan dengan kelompok padi varietas IR.64 dengan rerata 1,08. Pada indikator pupuk diperoleh nilai $\mathrm{p}$-value $0,000<\alpha$ 0,05, menunjukkan bahwa terdapat perbedaan yang signifikan antara kelompok padi varietas Ciherang dan IR.64 yang menunjukkan kelompok padi varietas IR.64 lebih efektif dengan rerata 5210,00 dibandingkan dengan kelompok padi varietas Ciherang dengan rerata 4456,7. Untuk indikator tenaga kerja diperoleh nilai $\mathrm{p}$-value $0,000<\alpha 0,05$, menunjukkan bahwa terdapat perbedaan yang signifikan antara kelompok padi varietas Ciherang dan IR.64 yang menunjukkan kelompok padi varietas IR.64 lebih efektif dengan rerata 1,09 dibandingkan dengan kelompok padi varietas Ciherang dengan rerata 5,41. Sedangkan indikator pestisida diperoleh nilai p-value $0,000<\alpha 0,05$, menunjukkan bahwa terdapat perbedaan yang signifikan antara kelompok padi varietas Ciherang dan IR.64 yang menunjukkan kelompok padi varietas IR.64 lebih efektif dengan rerata 5,53 
dibandingkan dengan kelompok padi varietas Ciherang dengan rerata 2,63.

Tabel 2. R/C Rasio Usahatani Padi Varietas Ciherang dan IR64

\begin{tabular}{lccc}
\hline \multirow{2}{*}{ Nilai Rerata } & Varietas & \multicolumn{2}{c}{ Uji Beda } \\
\cline { 2 - 4 } & Ciherang & IR.64 & \\
\hline Pendapatan & 1,89 & 2,18 & 0,029 \\
Benih & 1,15 & 1,08 & 0,000 \\
Pupuk & 4456,67 & 5210,00 & 0,000 \\
Tenaga & 5,41 & 1,09 & 0,000 \\
Kerja & 2,63 & 5,53 & 0,000 \\
Pestisida & 3,90 & 3,07 & \\
R/C & &
\end{tabular}

Signifikan pada $\alpha: 0,05(5 \%)$

Sumber : Data primer diolah, 2019.

Berdasarkan hasil uji Dependent Samples Test diperoleh nilai p-value untuk indikator benih $0,029<\alpha 0,05$, menunjukkan bahwa terdapat perbedaan yang signifikan antara kelompok padi varietas Ciherang dan IR.64. Hal ini menunjukkan kelompok padi varietas Ciherang lebih efektif dengan rerata 1,89 $\mathrm{m}^{2}$ dibandingkan dengan kelompok padi varietas IR.64 dengan rerata 2,18.

Berdasarkan hasil penelitian diperoleh nilai $\mathrm{R} / \mathrm{C}$ rasio untuk varietas Ciherang sebesar 3,90 dan varietas IR.64 sebesar 3,07 yang memiliki nilai R/C > 1 yang artinya usahatani padi varietas Ciherang dan IR.64 di Desa Kebondowo, Banyubiru, Kabupaten Semarang sangat layak untuk diusahakan.

\section{KESIMPULAN DAN SARAN}

\section{Kesimpulan}

Harga pupuk dan harga tenaga kerja merupakan faktor yang mempengaruhi pendapatan usahatani padi, sementara harga benih dan harga pestisida tidak. Pendapatan petani di Desa Kebondowo, Kecamatan Banyubiru, Kabupaten Semarang untuk varietas Ciherang ( $R p$ 1.855.374) lebih rendah dibandingkan dengan varietas IR.64 ( $\operatorname{Rp} 2.123 .763)$.

\section{Saran}

Mengingat harga pupuk dan harga tenaga kerja adalah faktor yang berpengaruh terhadap pendapatan petani padi, maka saran manajemen adalah supaya meminimalisir biaya pupuk dan biaya tenaga kerja agar pendapatan yang diterima petani lebih tinggi.

\section{DAFTAR PUSTAKA}

BBPADI. 2015. Retrieved from Balai Besar Penelitian Tanaman Padi:http://bbpadi.litbang. pertanian.go.id/

BPS. 2017. Impor beras Indonesia 2017. Retrieved from https://databoks.katadata.co.id/dat 
apublish/2016/12/28/2016-

importerbesar-berasal-dari-cina.

Cahyono. 2010. Analisis Keuntungan Petani Padi di Kecamatan Nogosari Kabupaten Boyolali. Skripsi.

Ghozali, I. 2001. Aplikasi Analisis Multivariate Dengan Program SPSS.

Listiani, R., A. Setiyadi dan S. I. Santoso. 2019. Analisis Pendapatan Usahatani Padi di Kecamatan Mlonggo Kabupaten Jepara. Agrisocionomics. Jurnal Sosial Ekonomi dan Kebijakan Pertanian. 3(1): 50-58.

Singgih, S. 2000. Latihan SPSS Statistik Parmetik. Gramedia. Jakarta.

Sugiyono. 2010. Statistika untuk Penelitian. Alfabeta. Bandung.

Suparmoko. 2002. Ekonomi Publik, Untuk Keuangan dan Pembangunan Daerah. Andi. Yogyakarta.

Suprihatno. 2009. Deskripsi Varietas Padi. Balai Besar Tanaman Padi. Subang.

Shinta, A. 2011. Ilmu Usahatani. Universitas Brawijaya Press. Malang.

Triharso. 2004. Dasar-Dasar Perlindungan Tanaman. Universitas Gadjah Mada Press. Yogyakarta. 